\title{
THE EFFECT OF A FALL IN FILTRATION RATE ON SOLUTE AND WATER EXCRETION IN HYDROPENIC MAN * $\dagger$
}

\author{
By MARVIN F. LEVITT, MARSHALL S. LEVY AND DEMETRA POLIMEROS \\ (From the Departments of Medicine and Pediatrics, The Mount Sinai Hospital, \\ New York, N. Y.)
}

(Submitted for publication July 22, 1958; accepted November 6, 1958)

Considerable attention has been focused on the relation between the quantity of solute filtered and urine concentration (1-3). It has been shown that as the filtered solute load is increased in hydropenic subjects, the concentration of the urine falls despite continued antidiuretic activity (1-4). A major action of the antidiuretic hormone (ADH) is to render the distal tubule more permeable to water and the fluid therein progressively less dilute before it reaches the concentrating segment (5-7). An increment in the quantity of solute filtered and unreabsorbed in the proximal tubule increases the solute load reaching the distal tubule and thereby reduces the diffusion coefficient of the distal tubular water (8). Furthermore, the continued extraction of solute in the distal tubule increases the volume of water freed for back diffusion $(7,8)$. The existing levels of circulating $\mathrm{ADH}$ might then prove relatively less effective in promoting maximum back diffusion of distal tubular water so that the concentration of the fluid leaving the distal tubule would fall below serum osmolality (8). The diluting effect of an increase in the filtered solute load in hydropenic subjects might relate to this factor of less complete back diffusion of distal tubular water as well as to the increase in volume reaching the concentrating segment. To delineate further the influence of variations in the rate of filtration of solute on urine concentration, experiments were performed in man during which the glomerular filtration rate (GFR) was reduced in the face of intense antidiuretic activity. Such experiments were performed in subjects without renal disease and in patients with frank renal failure of diverse etiology.

\footnotetext{
* Presented in abstract form at the Meetings of the Society of Clinical Investigation, May 5, 1958.

$\dagger$ Supported by a grant (No. A-277) from the National Institute of Arthritis and Metabolic Diseases, National Institutes of Health.
}

\section{MATERIALS AND METHODS}

Glomerular filtration rate was reduced for approximately two hours in 21 hydropenic subjects comprising three separate groups. Group Ia consisted of eight subjects with normal renal function, maintained on regular diets; Group Ib included six subjects with normal kidney function in whom the rate of sodium excretion had been markedly depressed. The latter group was prepared by the institution of a salt-free diet, containing $225 \mathrm{mg}$. of sodium, five days prior to the acute experiment. Fortyeight hours before the experiment, the oral administration of 9-alpha fluorohydrocortisone was started at a dosage level of $2 \mathrm{mg}$. every eight hours. Group II consisted of seven patients with frank renal failure of diverse etiologies.

Each patient received five units of Pitressin ${ }^{\circledR}$ Tannate in oil intramuscularly the night before, and was deprived of food and water for 16 hours prior to the experiment. The study was performed in the morning with the fasting patient remaining in bed. Catheterization was performed with a No. 18 multi-holed soft catheter or, in later experiments, a No. 18 malecott catheter. This latter type allows the catheter opening to lie flush with the internal urethral orifice, a position which permits an efficient bladder emptying without awkward and painful manipulation of the catheter. The overnight specimen was saved in a sterile syringe. A calibrated syringe was attached to the distal end of the catheter and the bladder was emptied every three minutes in order to estimate urine flow accurately at the bedside. The periods of very low urine flow could thus be terminated as soon as sufficient urine was collected.

A priming injection of inulin, sodium para-aminohippurate $(\mathrm{PAH})$, and two units of Pitressin ${ }^{\circledR}$ was administered intravenously. This was followed by a constant infusion of these substances dissolved in Ringer's lactate in quantities adequate to measure GFR and effective renal plasma flow (ERPF), and to insure maximal antidiuretic activity. (Pitressin was infused at a rate of $500 \mathrm{mU}$ per hour.) This solution was administered intravenously with a Bowman infusion pump at a constant rate of $0.5 \mathrm{ml}$. per minute. After a 45 to $60 \mathrm{~min}$ ute equilibration period, the bladder was emptied, rinsed with the overnight, inulin-free urine, and then with air. Thereafter three 30 minute control periods were completed and the bladder was emptied only with air.

The blood pressure was then reduced by the intravenous administration of 50 to $100 \mathrm{mg}$. of SC 1950 
(1-ethyl-2,6-dimethylluptidine ethobromide), ${ }^{1}$ a ganglionic blocking agent, and/or the application of venous tourniquets to the thighs. The drug alone was usually sufficient to lower the blood pressure in patients with any degree of hypertension; tourniquets and tilting were required in addition in the normotensive subjects. The hypotension was maintained for about two hours during which 3 to 4 more urine collection periods of approximately $45 \mathrm{~min}$ utes each were completed. Blood specimens were collected at appropriate intervals throughout the control and hypotensive periods. Each blood and urine sample was analyzed for total osmolality and inulin, $\mathrm{PAH}$, sodium, potassium, chloride and urea concentrations. Urine $\mathrm{pH}$ and $\mathrm{CO}_{2}$ content were determined in several experiments. Clearances were calculated by standard methods.

In the subjects in Group Ib, the maximum osmolality of the urine was measured before the salt-free diet was instituted. As in the preparation for an experiment, five units of Pitressin ${ }^{\circledR}$ in oil was administered the night before and the patient was subsequently deprived of all food and water for 16 to 18 hours. The following morning urine specimens were collected at 7 and 8 a.m. for the measurement of total osmolality.

Three normal subjects were exposed to identical experimental protocols but failed to sustain a measurable fall in glomerular filtration rate. This group, therefore, served as a control for the three experimental groups studied in which each subject underwent a fall in glomerular filtration rate of at least 20 per cent.

Osmolality was measured with a Bowman-Aminco freezing point depression apparatus (9). Sodium and potassium concentrations were determined with an internally standardized flame photometer, chloride by the Whitehorn modification of the Volhard method (10), urea by the micro-method of Steinitz using Conway units (11), inulin by Schreiner's method (12), and PAH by the method of Smith and co-workers (13).

\section{RESULTS}

During the three control periods in all of the experimental subjects, the urine osmolality tended to rise slightly. The mean increment per control period equalled $10 \mathrm{mOsm}$. per L. but the maximum increase in urine osmolality throughout the prehypotensive periods did not exceed $40 \mathrm{mOsm}$. per L. Accordingly, the separate control osmolalities, as well as the other separate control modalities measured, were averaged and presented as one control figure in Tables I through IV. In the three subjects in whom the GFR was not reduced 10 per cent or more, the urine osmolality continued to rise slightly at a rate not appreciably different from that noted during the prehypotensive

${ }^{1}$ This drug was generously supplied by the G. D. Searle Co., Chicago, Ill., through Dr. Irwin C. Winter, Clinical Director.

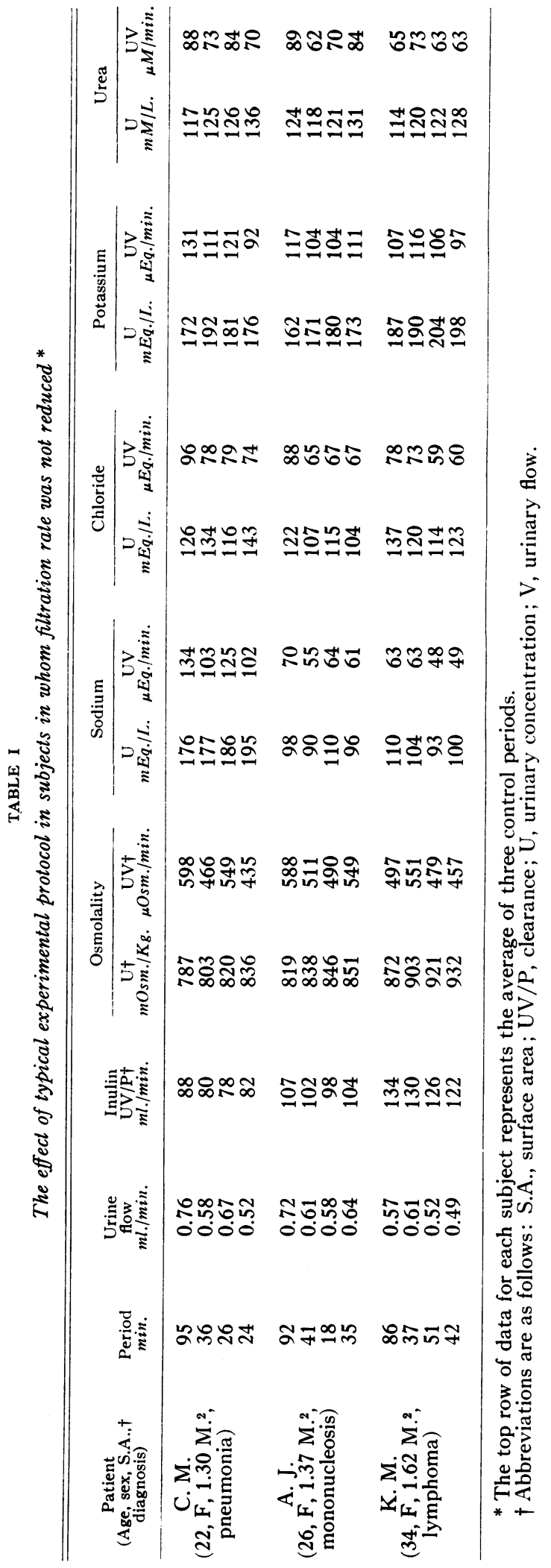




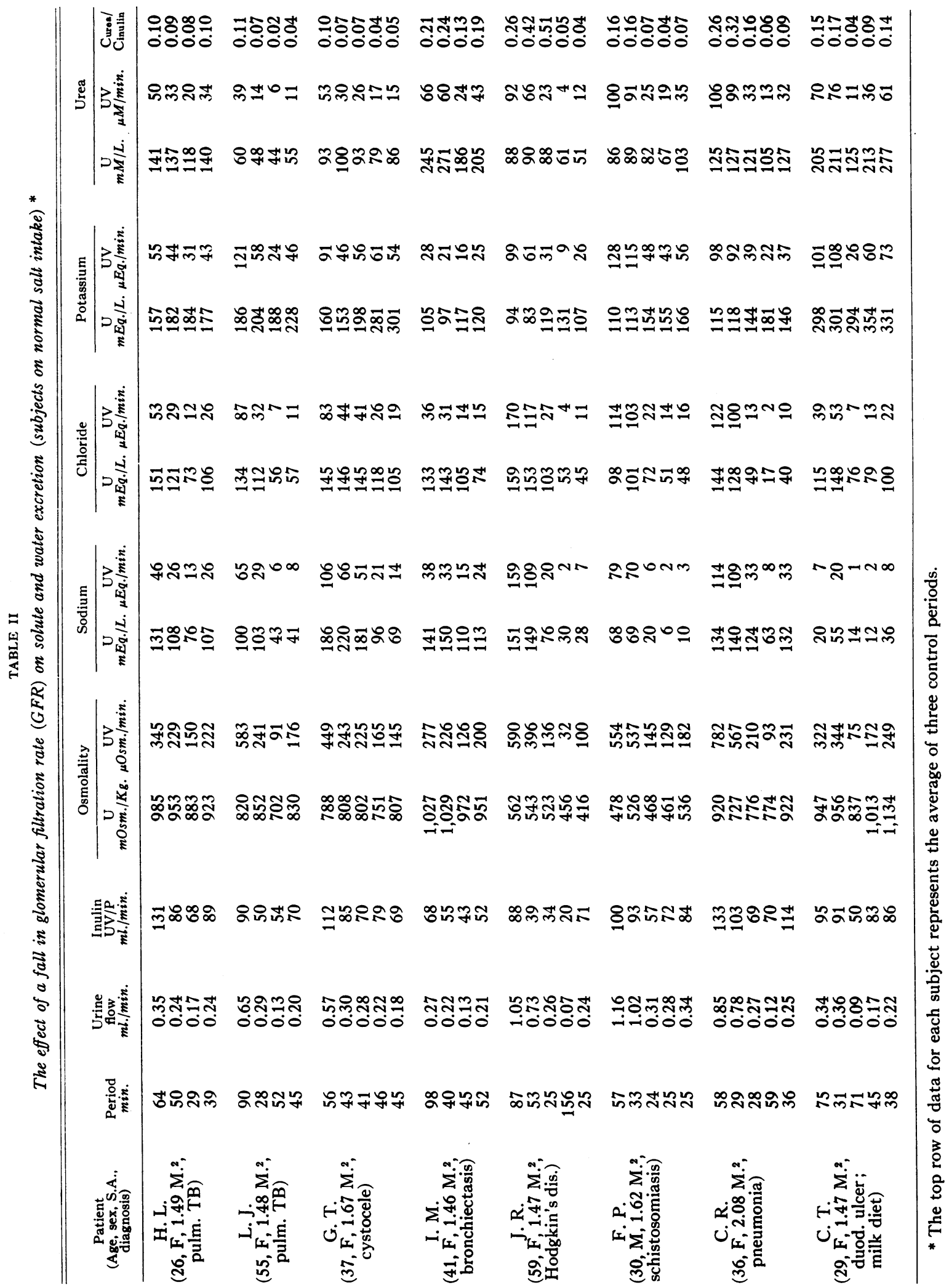


M. F. LeVitT, M. S. LeVy, AND D. POLIMERoS

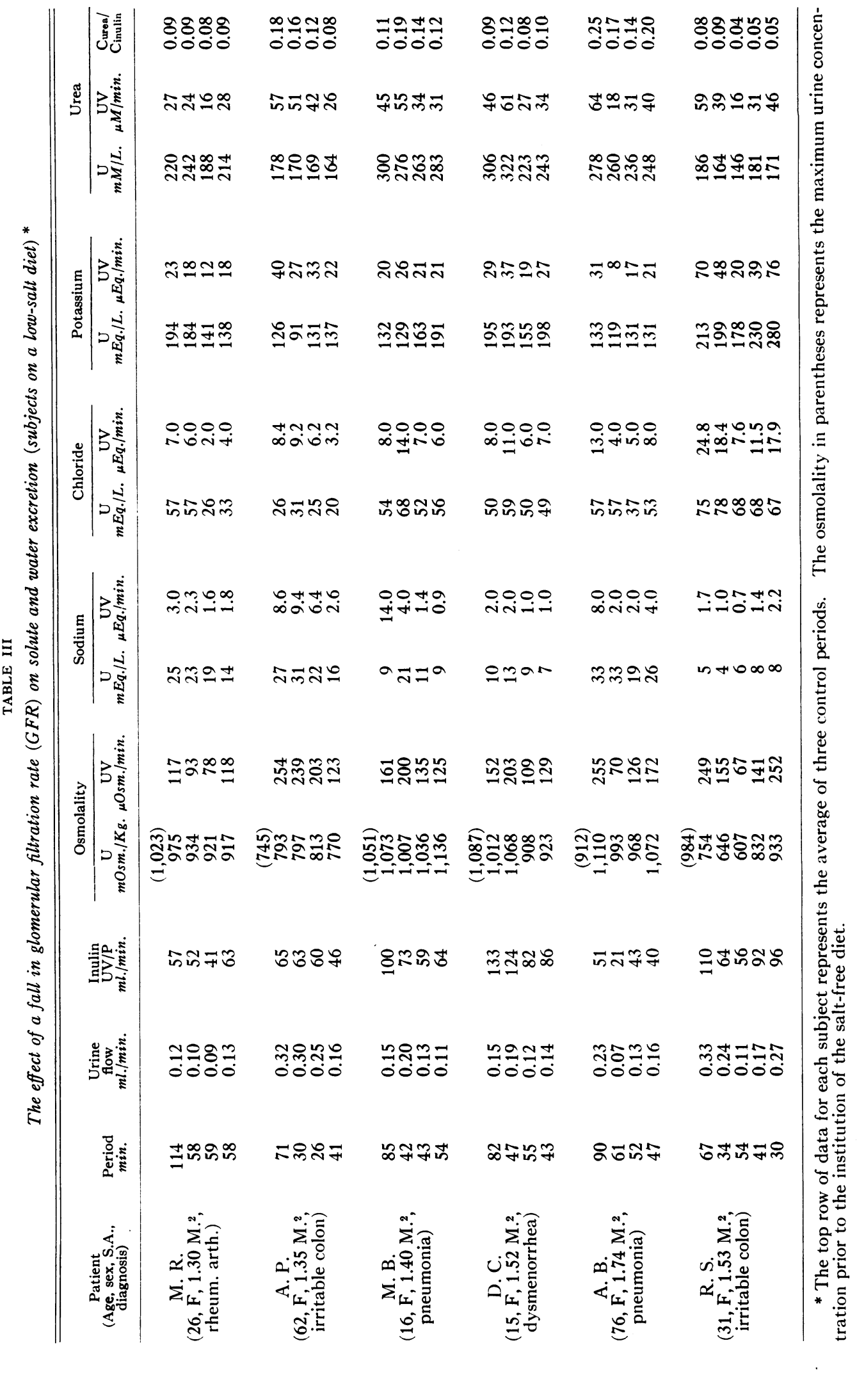


EFFECT OF DECREASED SOLUTE LOAD ON URINARY OSMOLALITY

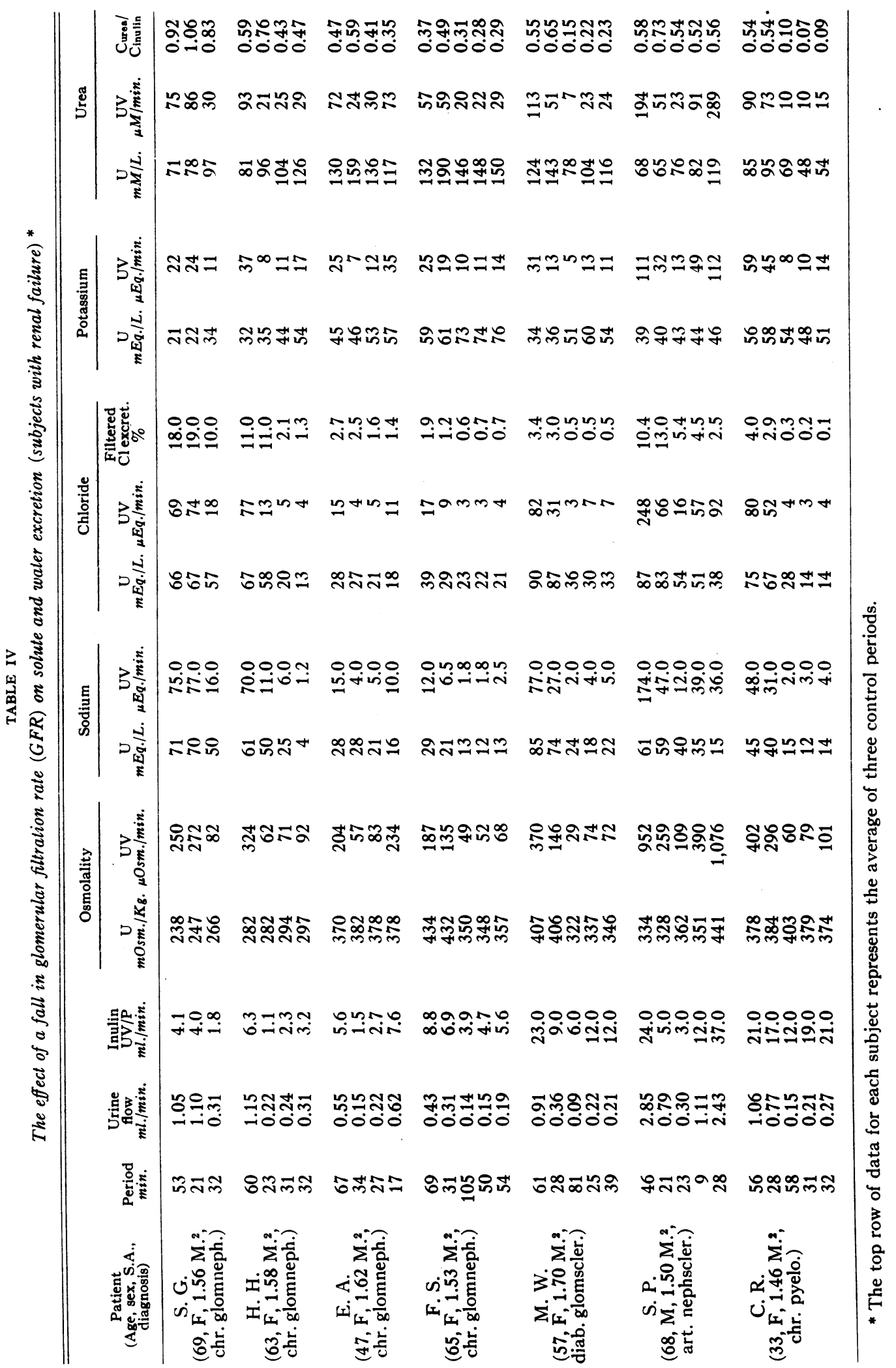


periods (Table I). In these subjects, no appreciable changes occurred in the rate of urea or electrolyte excretion.

In eight normal subjects ${ }^{2}$ maintained on a regular salt intake, the hypotension produced a fall in filtration rate (Table II). The maximum fall, generally achieved during the second experimental period, averaged 47 per cent and ranged between 37 and 77 per cent. In association with this change, there was a consistent decrease in urine flow from an average of $0.68 \mathrm{ml}$. per minute to $0.14 \mathrm{ml}$. per minute. In each subject in whom the filtration rate was reduced, there was a consistent drop in urine osmolality averaging $91 \mathrm{mOsm}$. per L. or approximately 11 per cent of control solute concentrations (Table II). These falls in total solute concentration occurred regardless of the degree of urine hypertonicity achieved during the control period. In four of the eight subjects a slight increase in urine osmolality was detected in the first experimental period prior to the maximum fall in glomerular filtration rate. The total rate of solute excretion declined proportionately more than the coincident decrease in filtration rate (Table II). Sodium and chloride concentrations in the urine fell markedly, averaging 55 and 46 per cent, respectively (Table II). In association with the pronounced decrease in urine flow, the rate of sodium and chloride excretion fell almost 90 per cent. Simultaneously, there occurred a consistent increase in the potassium concentration of the urine ranging from 13 to 87 per cent and averaging 39 per cent (Table II). The rate of potassium excretion, however, fell slightly more than 60 per cent or considerably less than the coincident decrement in chloride excretion. In four subjects, in whom it was measured, the reduction in filtration rate produced a decrease in urine $\mathrm{pH}$ and $\mathrm{CO}_{2}$ content.

During the period of reduced filtration rate, the urea concentration fell consistently, the decline ranging between 14 and $80 \mathrm{mOsm}$. per L. and averaging $34 \mathrm{mOsm}$. per L. (Table II). Accordingly there occurred a considerable fall in the rate of urea excretion and in the ratios of the urea to inulin clearance. This latter ratio diminished from a control average of 0.17 to 0.06 (Table II).

\footnotetext{
2 "Normal" is used only to denote the absence of any clinical or hemodynamic evidence of renal disease.
}

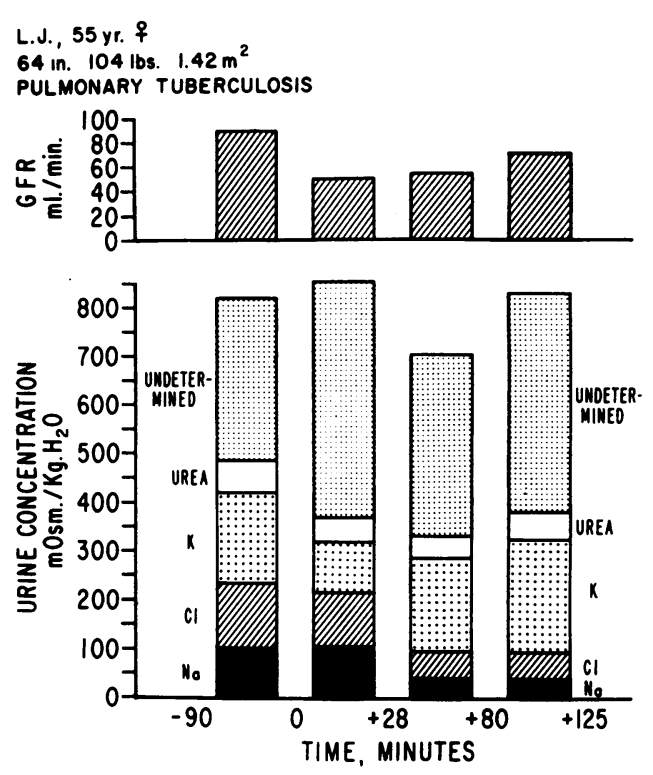

Fig. 1. Changes in Urine Solute Concentration Following a Fall in Filtration Rate in Hydropenic Subjects Without Renal Disease

The typical change in the solute concentration of the urine effected by a fall in filtration rate is presented in Figure 1. There occurred a considerable fall in salt concentration, a lesser decrease in the fraction composed of urea and a moderate rise in potassium concentration and in the concentration of the nonmeasured solute.

In the six subjects maintained on salt-free diets and treated with salt-retaining hormone, the hypotension produced a fall in filtration rate averaging 41 per cent and ranging from 27 to 59 per cent (Table III). Compared with Group Ia, the control rates of urine flow were considerably lower, averaging $0.21 \mathrm{ml}$. per minute and falling to 0.11 ml. per minute (Table III). As in the previous experimental group there was a consistent fall in urine osmolality averaging $62 \mathrm{mOsm}$. per L. or 9 per cent of the control solute concentration (Table III). The control maximum urine osmolalities obtained on the experimental day did not differ appreciably from similar measurements performed prior to the institution of the special diet and hormone therapy (Table III). The proportional changes in salt concentration and the rate of salt excretion were similar to those observed in Group Ia but the control rates of salt excretion were so low that the absolute changes tended to be small. Changes in potassium excretion were similar to 
those noted in Group Ia. As in Group Ia there occurred a consistent fall in urine urea concentration averaging $26 \mathrm{mOsm}$. per L. (Table III). However, the decrease in urea to inulin clearance ratio was not as marked as those reported above (Table III).

In seven patients with renal failure, comparable periods of experimental hypotension produced a maximum fall in filtration rate averaging 67 per cent (Table IV). The control rates of urine flow were considerably higher than that in the previous groups, averaging $1.14 \mathrm{ml}$. per minute and falling to $0.19 \mathrm{ml}$. per minute. The changes in urinary osmolality differed from those observed in the previous groups. In five patients, there was a slight increase in urine osmolality whereas two showed the falls characteristic of the normal subjects (Table IV). Compared to the normal groups a much higher percentage of the filtered solute and chloride was excreted in the urine (averages of 11 and 6 per cent, respectively). After the filtration rate was reduced, there occurred a very conspicuous fall in the concentration and rate of excretion of salt (Table IV) so that the percentage of the filtered salt load excreted in the urine more closely approached this comparable fraction observed during the control periods in the normal subjects. The changes in the concentration and rate of excretion of potassium were very similar to those observed in the normal groups (Table IV).

The changes in urea concentration corresponded to those of total solute concentration, five patients showing a slight increase in urea concentration and two a moderate decline (Table IV). The ratio between the urea and inulin clearance in this group far exceeded that noted in the normal groups and averaged 0.57 (Table III). Following the fall in filtration rate, this ratio decreased considerably but hardly reached the control ratio observed in the normal subjects.

Typical changes in the solute composition of the urine in a uremic subject in whom filtration rate was reduced are presented in Figure 2. The slight increase in total solute concentration is associated with a slight increase in urea and potassium concentration but a marked fall in salt concentration.

In all three groups, the proportionate fall in $\mathrm{PAH}$ clearance was similar to that of the inulin
H.H., 63 yr. $\$$

63 in. 125 lbs. $1.5 \mathrm{~m}^{2}$

CHRONIC GLOMERULONEPHRITIS
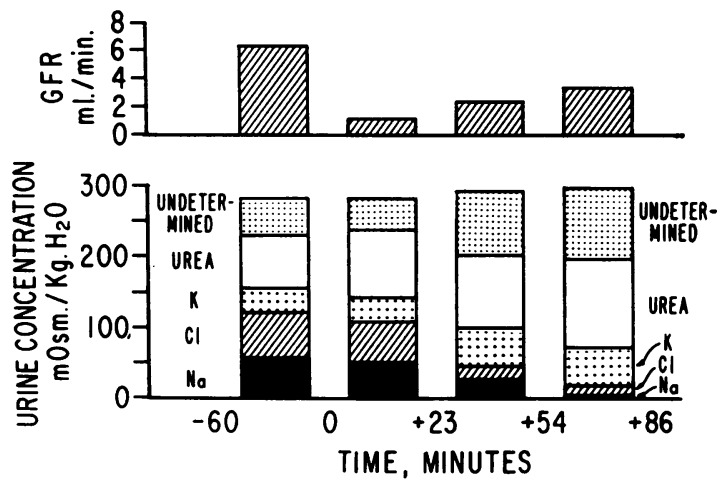

Fig. 2. Changes in Urine Solute Concentration Following a Fall in Filtration Rate in Hydropenic Subjects with Frank Renal Failure

clearance so that the filtration fraction remained unchanged.

In Groups Ia and Ib the filtration rate tended to return toward control values in the final experimental period (Tables I and II). This increase was often associated with a substantial rise in the urine osmolality toward, and even above, the control concentrations (Tables II and III).

\section{DISCUSSION}

On the basis of the data presented, it seems evident that 14 subjects in the normal group, both on the salt-free and on the regular diets, sustained a diminution in GFR ranging between 30 and 50 per cent which persisted for at least one hour. Although the absolute GFR measurements in the subjects with frank renal failure may have limited value, it appears that these subjects underwent a percentile fall in filtration rate at least as great as that recorded in the normal subjects.

Because of the low rates of urine flow, particularly during the hypotensive periods, the measured urinary concentrations represent parameters from urine that was formed some time prior to collection. Consequently, the observed osmolalities probably correspond best to the filtration rate recorded during the preceding period. Throughout the control periods, the urine osmolality tended to rise slightly because of continuing fluid deprivation and Pitressin ${ }^{\circledR}$ administration. This small but progressive rise in urine osmolality was particularly evident in those subjects in whom the ex- 
perimental conditions failed to induce a fall in GFR (Table I). This gradual increment in urine concentration prior to the fall in filtration rate tends to underscore the consistent fall in urine osmolality noted in those normal subjects in whom the GFR was reduced.

According to present concepts of renal function, a fall in filtration rate in hydropenic, Pitressin ${ }^{{ }_{-}}$ infused subjects should enhance maximum back diffusion of water from the distal convoluted tubule assuring a peak concentration equal to serum osmolality $(7,8,14-16)$. Furthermore, this stimulus appreciably reduces the water and solute load reaching the collecting duct. The continued extraction of solute-free water at this concentrating segment might therefore be expected to increase the urine osmolality to its maximum. Such an increase was observed in the first experimental period of several normal subjects (Tables II and III, Figure 3$).^{3}$ That these experimental conditions ultimately effected a fall in urine osmolality in all the normal subjects in whom the GFR was reduced (Figure 3 ) suggests that a considerable reduction in the rate of filtration of solute diminished the efficiency of the concentrating segment.

Considerable evidence suggests that urine is concentrated in the collecting duct by the flow of tubular fluid past a hypertonic medullary interstitial fluid $(15,16)$. According to this view, solute, particularly sodium, is actively transferred into this site by a process, the exact mechanism of

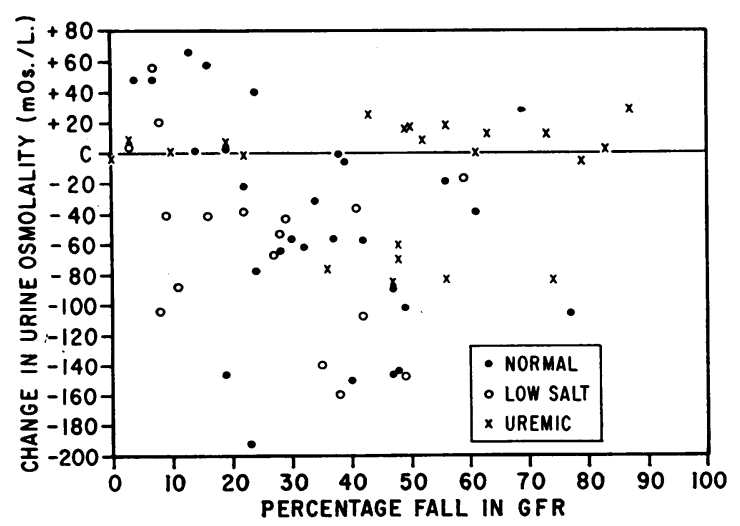

Fig. 3. Percentage Changes in Filtration Rate Plotted Against Absolute Change in Total Urine Solute Concentration in All Three Groups Studied

${ }^{3}$ In fact, this inconstant increase in urine osmolality may simply reflect the continuing slight increase in urine osmolality noted during the control periods (Table I). which remains uncertain (15-17). Of equal relevance to this hypothesis is the presence in the medulla of a rich hairpin capillary plexus which creates a counter-current circulation tending to trap whatever solute is deposited in this site (16, 17).

The reduction in renal and presumably medullary blood flow produced in these experiments might be the factor responsible for reducing the concentration of the urine. However, if medullary ischemia does prevent the elaboration of a maximally concentrated urine, it would be difficult to explain the slight increase in urine solute concentration noted in the majority of the uremic subjects. Furthermore this hypothesis would not concur with the reported increase in urine concentration produced by a comparable stimulus in dog and man with diabetes insipidus $(6,7,18)$. In terms of the counter-current hypothesis, a reduction in medullary flow should enhance the solute trapping effect and thereby increase the quantity of solute confined within the medulla and the osmolality of the urine (17).

It is conceivable that a fall in filtered load so reduces the quantity of sodium escaping absorption by the proximal tubule that the amount remaining for transfer into the medulla is too small to achieve maximum urine concentration. In the subjects in Group Ib, the combination of dietary sodium restriction and the administration of a potent sodium retaining hormone probably reduced the quantity of sodium escaping proximal reabsorption. Nevertheless, these subjects were able to concentrate their urine to a degree comparable to that achieved prior to sodium restriction. When the filtration rate was reduced in these patients, further depressing the flow of sodium beyond the proximal tubule, the falls in urine osmolality were not significantly different from those observed in the untreated subjects. This finding suggests that the decrease in filtration rate did not appreciably limit the quantity of sodium available for transfer into the medulla. These considerations tend to rule out renal ischemia and a diminished filtered sodium load as the explanation for the observed fall in urine osmolality in these experiments.

Another solute which accumulates in the hypertonic medulla is urea. Presumably urea enters this site by a process of passive diffusion, the rate 
of which is dependent upon the concentration gradient between fluid in the collecting tubule and that in the medulla (17). This gradient is produced, in large part, by the rapid outward diffusion of water as the tubular fluid enters the area of medullary hypertonicity. A fall in filtration rate with continued back diffusion of urea throughout the length of the tubule markedly reduces the clearance ratios of urea to inulin and, accordingly, the quantity of urea entering the concentrating segment. The rate of back diffusion of urea at this site would therefore be considerably reduced and the effect on total medullary osmolality would be diminished. As the urea concentration at this medullary site falls, the back diffusion of whatever tubular urea reaches it would be more complete. Because the rate of total solute and urea entering this segment is much reduced, the continued back diffusion of urea at the concentrating segment or any more distal site would effect a more conspicuous fall in total solute concentration of the urine. ${ }^{4}$ The combined effect of a fall in the rate of back diffusion of urea on total medullary concentration and of the continuing back diffusion of urea at, or distal to, the concentrating segment would explain the net fall in urine solute and urea concentration observed in normal subjects.

\footnotetext{
${ }^{4}$ Since these experiments were completed, Levinsky and Berliner have shown that a small concentrated volume of urine left in the bladder for 30 minutes may lose a considerable fraction of its urea, presumably, via a process of passive back diffusion (19). While an undetermined fraction of the total fall in urine osmolality noted in these experiments may result from the continuing back diffusion of urea at the concentrating segment or any site distal thereto, it is difficult to ascribe the entire drop in osmolality to the back diffusion of urea in the bladder per se. During the hypotensive period, the bladder was constantly drained and emptied so that each period could be terminated as soon as $6 \mathrm{ml}$. of urine was obtained. Consequently, the urine was not permitted to lie in contact with the bladder mucosa for more than five minutes. Furthermore, in the uremic subjects where the same back diffusion of bladder urea would be expected, the urine urea concentration rose during the period of hypotension. Regardless of the length of the period of urine collection, no fall in urine osmolality or urea concentration occurred during any control period or any experimental period not preceded by a considerable fall in glomerular filtration rate. Finally, in each experimental period in which a fall in urine osmolality occurred, this decrease exceeded the simultaneous drop in urinary concentration of urea.
}

Many reports in the literature attest to the role of high protein and urea loads in producing maximum concentration of the urine $(20-22)$. The fall in urine osmolality effected by protein and urea deprivation may to some extent relate to the reduced urea loads available for back diffusion in the collecting duct.

This hypothesis, proposed to explain the changes in the normal subject, is in accord with the opposite changes in urine solute concentration noted in the patients with renal failure. The relatively larger quantities of filtered urea excreted, as evident in the high urea to inulin clearance ratios, tend to impose an osmotic diuresis on the operating nephrons. This circumstance assures that a relatively good urea load may reach the collecting duct after the fall in filtration rate. The effects of the fall in urea load on the concentrating segment would therefore be muted. Further, the osmotic diuresis in the uremic patient may, even with a Pitressin ${ }^{\circledR}$ infusion, prevent maximum back diffusion of distal tubular water (8). The increment in the distal tubular fluid concentration effected by a reduced rate of flow might tend to obscure the simultaneous reduction in the efficiency of the concentrating segment. This dual effect may resolve the discrepancy between a net increase in urine concentration produced by a fall in filtration rate in diabetes insipidus dogs with the failure in these same experiments to produce a maximally concentrated urine $(7)$.

It has been reported that in the dog comparable experiments produced similar but more marked falls in urine concentration (23). These experiments differ from those reported here in that much more sizeable reductions in filtration rate were attainable in the experimental animal.

The fall in urine concentration recorded in these experiments seems best explained by, and therefore supports, the hypothesis that urine is concentrated by the flow of tubular fluid past an area of medullary hypertonicity. However, these data may also be explained in other terms. It is conceivable, for example, that the fall in urine solute concentration might be related to a reduction in blood supply to separate populations of nephrons. The reduced renal perfusion precipitated by experimental hypotension may eliminate filtration in those nephrons dipping deeply into the medulla and supply blood only to those with shorter tu- 
bules producing a more dilute urine. It has also been suggested that the remaining nephrons in operation may be exposed to an increased filtered load and act as if under the influence of an osmotic diuresis with a reduction in urine osmolality (24).

The fact that considerable falls in filtration rate may occur without any measurable fall in glucose $\mathrm{Tm}$ argues against the possibility that any appreciable number of nephrons have been cut out of circulation (25). According to this alternate hypothesis, the fall of 90 to 95 per cent in salt excretion associated with a 50 per cent fall in filtration rate would demand that half of the operating nephrons normally excrete only 5 to 10 per cent of the salt. This seems unlikely, particularly if the nephrons remaining in operation represent those with the shortest tubules and least opportunity for salt reabsorption. That the operating nephrons are subject to a solute diuresis is not borne out by the proportionately greater fall in solute excretion than in filtration rate (Tables II, III). It is therefore difficult to explain these observed changes in solute and water excretion on the basis of alterations in the nephron population remaining in operation. It seems instead that some reduction in filtration rate was produced in virtually all glomeruli-an assumption inherent in the original hypothesis.

Proportionately large falls in salt excretion following a reduction in the filtration rate of normal man and dog have been previously recorded (2628 ). This conspicuous change has been attributed to the prolonged contact of the glomerular filtrate with the salt absorbing tubules. The lesser changes in the rate of potassium excretion has likewise been emphasized. It has been argued that the rate of potassium excretion plunges only when the quantity of sodium available to the distal or exchanging segment begins to fall appreciably (29). The data in the normal subjects following a fall in filtration rate are in accord with these previous observations and hypotheses.

Similar changes in salt and potassium excretion following a comparable stimulus in uremic subjects suggest that the operating nephrons retain the capacity for considerable salt absorption. The failure of the uremic subjects to absorb comparable fractions of the filtered load therefore seems to stem from an osmotic diuresis imposed by the urea load or by a glomerular preponderance in the remaining nephrons (30). The elimination of the glomerular-tubular imbalance in these subjects then leads to a more complete reabsorption of filtered salt similar to that noted in the normals.

\section{SUM MARY}

1. Glomerular filtration rate was reduced at least 50 per cent for one to two hours in three groups of hydropenic subjects. These three groups consisted, respectively, of subjects without renal disease on normal salt intakes, similar subjects on salt-free diets treated with salt-retaining hormone, and patients with frank renal failure.

2. In each of the first two groups, comparable falls in filtration rate produced decreases in total urine osmolality averaging 10 per cent. In the majority of the subjects with renal failure, a fall in filtration rate produced a slight increase in urine osmolality.

3. In all three groups, the fall in filtration rate was associated with a marked drop in the rate of water and salt excretion, but with a lesser fall in the rate of potassium excretion.

\section{REFERENCES}

1. Mudge, G., Foulks, J., and Gilman, A. Effect of urea diuresis on renal excretion of electrolytes. Amer. J. Physiol. 1949, 158, 218.

2. Rapoport, S., Brodsky, W. A., West, C. D., and Mackler, B. Urinary flow and excretion of solutes during osmotic diuresis in hydropenic man. Amer. J. Physiol. 1949, 156, 433.

3. Wesson, L. G., Jr., Anslow, W. P., Jr., and Smith, $\mathrm{H}$. W. The excretion of strong electrolytes. Bull. N. Y. Acad. Med. 1948, 24, 586.

4. de Wardener, H. E., and del Greco, F. The influence of solute excretion rate on the production of a hypotonic urine in man. Clin. Sci. 1955, 14, 715.

5. Wirz, H. Der osmotische Druck in den corticalen Tubuli der Rattenniere. Helv. physiol. pharmacol. Acta 1956, 14, 353.

6. del Greco, F., and de Wardener, H. E. The effect on urine osmolarity of a transient reduction in glomerular filtration rate and solute output during a 'water' diuresis. J. Physiol. 1956, 131, 307.

7. Berliner, R. W., and Davidson, D. G. Production of hypertonic urine in the absence of pituitary antidiuretic hormone. J. clin. Invest. 1957, 36, 1416.

8. Orloff, J., Wagner, H. N., Jr., and Davidson, D. G. The effect of variations in solute excretion and vasopressin dosage on the excretion of water in the dog. J. clin. Invest. 1958, 37, 458. 
9. Bowman, R. L., Trantham, H. V., and Caulfield, P. A. An instrument and method for rapid, dependable determination of freezing-point depression. J. Lab. clin. Med. 1954, 43, 310.

10. Whitehorn, J. C. Concerning chloride determinations by the modified Volhard titration. J. biol. Chem. 1927, 74, 299.

11. Steinitz, K. The determination of urea in blood and urine by Conway units. J. Lab. clin. Med. 1939, 25, 288.

12. Schreiner, G. E. Determination of inulin by means of resorcinol. Proc. Soc. exp. Biol. (N. Y.) 1950, 74, 117.

13. Smith, H. W., Finkelstein, N., Aliminosa, L., Crawford, B., and Graber, M. The renal clearances of substituted hippuric acid derivatives and other aromatic acids in dog and man. J. clin. Invest. 1945, 24, 388.

14. Walker, A. M., Bott, P. A., Oliver, , J., and MacDowell, M. C. The collection and analysis of fluid from single nephrons of the mammalian kidney. Amer. J. Physiol. 1941, 134, 580.

15. Wirz, $\mathrm{H}$. The location of antidiuretic action in the mammalian kidney in The Neurohypophysis, $\mathrm{H}$. Heller, Ed. Proceedings of the 8th symposium of the Colston Research Society. New York, Academic Press Inc. 1957, p. 157.

16. Wirz, H., Hargitay, B., and Kuhn, W. Lokalisation des Konzentrierungsprozesses in der Niere durch direkte Kryoskopie. Helv. physiol. pharmacol. Acta 1951, 9, 196.

17. Berliner, R. W., Levinsky, N. G., Davidson, D. G., and Eden, M. Dilution and concentration of the urine and the action of antidiuretic hormone. Amer. J. Med. 1958, 24, 730.

18. Kleeman, C. R., Maxwell, M. H., and Rockney, R. Production of hypertonic urine in humans in the probable absence of antidiuretic hormone. Proc. Soc. exp. Biol. (N. Y.) 1957, 96, 189.

19. Levinsky, N. G., and Berliner, R. W. Solute permeability of the lower urinary tract. In press.

20. Addis, T., and Shevky, M. C. A test of the capacity of the kidney to produce a urine of high specific gravity. Arch. intern. Med. 1922, 30, 559.

21. Epstein, F. H., Kleeman, C. R., Pursel, S., and Hendrikx, A. The effect of feeding protein and urea on the renal concentrating process. J. clin. Invest. 1957, 36, 635.

22. Hayman, J. M., Jr., Shumway, N. P., Dumke, P., and Miller, M. Experimental hyposthenuria. J. clin. Invest. 1939, 18, 195.

23. Levinsky, N. G., Davidson, D. G., and Berliner, R. W. Effects of reduced glomerular filtration on urine concentration in the presence of antidiuretic hormone (abstract). J. clin. Invest. 1958, 37, 910.

24. Blake, W. D. "Low pressure" kidney and the water concentrating mechanism (abstract). J. clin. Invest. $1958,37,878$.

25. Thompson, D. D., Barrett, M. J., and Pitts, R. F. Significance of glomerular perfusion in relation to variability of filtration rate. Amer. J. Physiol. 1951, 167, 546.

26. Lauson, H. D., and Thompson, D. D. Effects in dogs of decrease in glomerular filtration rate on cation excretion during intravenous administration of unreabsorbable anions. Amer. J. Physiol. 1958, 192, 198.

27. Mokotoff, R., Ross, G., and Leiter, L. Renal plasma flow and sodium reabsorption and excretion in congestive heart failure. J. clin. Invest. 1948, $27,1$.

28. Levitt, M. F., Turner, L. B., and Sweet, A. Y. The effect of experimental venous obstruction on salt and water distribution and excretion in man. J. clin. Invest. 1952, 31, 885.

29. Berliner, R. W., Kennedy, T. J., Jr., and Orloff, J. Factors affecting the transport of potassium and hydrogen ions by the renal tubules. Arch. int. Pharmacodyn. 1954, 97, 299.

30. Fremont-Smith, F., Fremont-Smith, M., Dailey, M. E., Solomon, P., Stetten, D., Jr., and Carroll, M. P. Studies in edema. I. The mechanism of water diuresis in man (abstract). J. clin. Invest. 1930, 9, 7.

\section{SPECIAL NOTICE TO SUBSCRIBERS}

Post Offices will no longer forward the Journal when you move.

Please notify The Journal of Clinical Investigation, Business

Office, 333 Cedar Street, New Haven 11, Conn., at once when you have a change of address, and do not omit the zone number if there is one. 